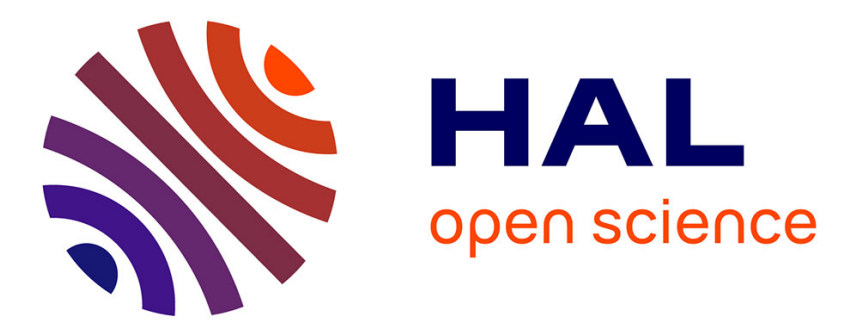

\title{
Atmospheric degradation of pyridine: UV absorption spectrum and reaction with $\mathrm{OH}$ radicals and $\mathrm{O} 3$
}

M. Errami, Gisèle El Dib, M. Cazaunau, E. Roth, R. Salghi, Abdelwahid Mellouki, A. Chakir

\section{- To cite this version:}

M. Errami, Gisèle El Dib, M. Cazaunau, E. Roth, R. Salghi, et al.. Atmospheric degradation of pyridine: UV absorption spectrum and reaction with $\mathrm{OH}$ radicals and O3. Chemical Physics Letters, 2016, 662, pp.141-145. 10.1016/j.cplett.2016.09.030 . hal-01380706

HAL Id: hal-01380706

https://hal-univ-rennes1.archives-ouvertes.fr/hal-01380706

Submitted on 24 Nov 2016

HAL is a multi-disciplinary open access archive for the deposit and dissemination of scientific research documents, whether they are published or not. The documents may come from teaching and research institutions in France or abroad, or from public or private research centers.
L'archive ouverte pluridisciplinaire HAL, est destinée au dépôt et à la diffusion de documents scientifiques de niveau recherche, publiés ou non, émanant des établissements d'enseignement et de recherche français ou étrangers, des laboratoires publics ou privés. 


\title{
Atmospheric degradation of Pyridine: UV Absorption Spectrum and reaction with $\mathrm{OH}$ radicals and $\mathrm{O}_{3}$
}

\author{
M. Errami ${ }^{1,2}$, G. El Dib ${ }^{3}$, M. Cazaunau ${ }^{4}$, E. Roth ${ }^{1}$, R. Salghi ${ }^{2}$, A. Mellouki $^{4}$, A. Chakir ${ }^{1}$ \\ ${ }^{1}$ GSMA, UMR CNRS 7331, Université de Reims Champagne Ardenne, U.F.R. Sciences Exactes et Naturelles \\ Moulin de la Housse, B.P. 1039, 51687 Reims, France \\ ${ }^{2}$ Equipe de Génie de l'Environnement et de Biotechnologie, ENSA, Université Ibn Zohr, Agadir, Morocco. \\ ${ }^{3}$ Département de Physique Moléculaire, Institut de Physique de Rennes, UMR 6251 du CNRS - Université de \\ Rennes 1, Bat. 11c, Campus de Beaulieu, 35042 Rennes Cedex, France. \\ ${ }^{4}$ ICARE-CNRS/OSUC, 1C Avenue de la recherche scientifique 45071, Orléans Cedex 02, France
}

\begin{abstract}
:
The UV absorption spectrum of pyridine and its gas phase reactions with $\mathrm{OH}$ radicals and $\mathrm{O}_{3}$ were investigated. UV absorption cross-sections were determined by using a $\mathrm{D}_{2}$-lamp system in the range 200 - $350 \mathrm{~nm}$. The kinetic studies were carried out at room temperature and atmospheric pressure of purified air. The rate coefficient for the reaction of pyridine with $\mathrm{OH}$ was determined relative to that with acetone while that with $\mathrm{O}_{3}$ was measured under pseudo first order conditions. The rate coefficients obtained are (in $\mathrm{cm}^{3}$ molecule $\mathrm{s}^{-1}$ ): $\mathrm{k}(\mathrm{OH}+$ Pyridine $)=(5.40 \pm 0.80) \times 10^{-13}$ and $\mathrm{k}\left(\mathrm{O}_{3}+\right.$ Pyridine $)=(3.28 \pm 1.70) \times 10^{-20}$.
\end{abstract}

Keywords: kinetics, UV absorption cross-sections, rate coefficient, tropospheric lifetimes, $\mathrm{OH}$ radicals, Ozone, nitrogen containing aromatic compounds, atmospheric simulation chamber

${ }^{* 1}$ Corresponding author : E mail address : abdel.chakir@univ-reims.fr ; Phone number: 0033326913263 


\section{Introduction:}

Pyridine $\left(\mathrm{C}_{5} \mathrm{H}_{5} \mathrm{~N}\right)$, a heterocyclic nitrogen-containing organic compound, is used as intermediate or solvent in agrochemical and pharmaceutical industries such as the synthesis of vitamins, sulphamides, disinfecting products, dyes and explosives, rubber and paint, in the drilling of fuel and gases and in food industries [1,2]. Because of its relatively high vapour pressure $\left(\approx 18\right.$ torr at $20^{\circ} \mathrm{C}$ ) a substantial quantity may escape into the atmosphere during its use. Pyridine may also be released into the atmosphere as primary pollutant from numerous sources such as biomass burning, automobile exhaust, coal tars and tobacco smoke $[3,4,5]$. Due to the localised and sometimes irregular nature of the sources, the concentration of pyridine is expected to be highly variable with time and location. The presence of pyridine ion in the clean air of Mauna Loa Observatory, Hawaii, suggests a long atmospheric lifetime of its parent neutral species [6].

Similarly to other volatile organic compounds, once in the atmosphere, pyridine may be removed by sunlight induced photolysis and/or chemical reactions with atmospheric oxidants such as $\mathrm{OH}$ and $\mathrm{NO}_{3}$ radicals, $\mathrm{Cl}$ atoms and ozone [2]. The atmospheric persistence of pyridine can be estimated using the kinetic parameters of these reactions. However, so far, the atmospheric degradation of pyridine has been subject to only a limited number of studies. The rate coefficient of the reaction of $\mathrm{OH}$ with pyridine has been measured only by two groups [2,7] while the reaction of pyridine with ozone has been investigated only once [2]. In order to better define the atmospheric fate of pyridine, its reactions with the atmospheric oxidants should be well characterized. For this purpose, we have conducted studies on its reactions with $\mathrm{OH}$ radicals and ozone. In addition, we have determined its UV-VIS absorption cross sections in order to evaluate the photolysis as atmospheric loss process. The obtained data are compared with the previous determinations and the atmospheric lifetime of pyridine is estimated using the measured parameters.

\section{Experimental:}

UV absorption spectrum device: The UV absorption spectrum of pyridine was measured at GSMA-Reims using a $\mathrm{D}_{2}$ Lamp-Monochromator System. Experiments were carried out between 200 and $350 \mathrm{~nm}$ at temperature $353 \pm 1 \mathrm{~K}$, in order to avoid the loss of pyridine to the walls, and under static conditions. The experimental set up and procedure used in this work have been presented in details in previous studies [8,9], therefore, only a brief description is given here. 
A $30 \mathrm{~W}$ deuterium lamp was used as the UV source. The light was focused into a calibrated spectrophotometer (HR 640) equipped with a 2400 line $\mathrm{mm}^{-1}$ grating and a dispersion of $0.26 \mathrm{~nm} \mathrm{~mm}{ }^{-1}$. At the exit slit of the monochromator, the beam passes through the absorption pyrex cell of $50 \mathrm{~cm}$ of length and $2 \mathrm{~cm}$ of diameter equipped with quartz optical windows. The signal is then measured by a Hamamatsu R 955 photomultiplier tube. Vapours of pyridine were introduced into the absorption cell under vacuum. The pressure of pyridine inside the cell was varied from 0.14 to 9.8 Torr and was measured by $(0-10)$ Torr MKS Baratron capacitance manometers at the beginning and the end of each measurement, in order to check for the stability of the concentration. The temperature was measured by platinum resistance sensors positioned at the two extremities of the cell. The absorption crosssection $\left(\sigma_{\lambda}\right)$ values at a given wavelength $\lambda$ were determined using the Lambert-Beer's law (1):

$$
\sigma_{\lambda}=\ln \left[\frac{I_{0}(\lambda)-I_{n}(\lambda)}{I(\lambda)-I_{n}(\lambda)}\right] \times \frac{R \times T}{P \times l \times N_{A}}
$$

Where $I_{n}(\lambda)$ is the spectrophotometer background noise, $I_{0}(\lambda)$ is the intensity of the issued radiation under vacuum in the absence of pyridine and $I(\lambda)$ is the transmitted intensity measured at each wavelength in the presence of pyridine. $P$ is the pressure (in Pascal), $T$ the temperature (in kelvin), $\downarrow$ the optical path, $R$ the gas constant and $N_{A}$ the Avogadro's number. The concentrations introduced in the absorption cell and the path lengths were chosen in such way to obtain optical density values between 0.1 and 2, conditions for which the cross-section is determined with good accuracy.

Simulation Chamber: The kinetic studies of the reaction of pyridine with $\mathrm{OH}$ and $\mathrm{O}_{3}$ were conducted in $\mathrm{P} \sim(760 \pm 5)$ Torr of air at $\mathrm{T}=298 \pm 2 \mathrm{~K}$ using a simulation chamber at ICARE-CNRS (Orléans). The experimental set up has been described in details earlier [10,11] therefore, it will only be presented briefly here.

The simulation chamber is made of Teflon with a volume of $7.3 \mathrm{~m}^{3}$ and a surface/volume ratio of $3 \mathrm{~m}^{-1}$. A calibrated gas cylinder equipped with pressure sensors was used to introduce gas reactants into the chamber. Vapours of liquid reactants were introduced into the chamber by placing a known volume in a bubbler which was then flushed by purified air. In order to ensure rapid mixing (2 minutes) of reactants, two fans made of Teflon were used. The pressure in the chamber was continuously kept slightly above the atmospheric pressure in order to avoid contamination from outside air. Air purification system (Donaldson Ultrafilter, 
Deutschland $\mathrm{GmbH}$ ) equipped with an adsorption dryer was used to generate purified air with residual concentrations of ozone and hydrocarbons below than $1 \mathrm{ppb}$. Temperature and relative humidity data were continuously measured by a combined sensor. Calibrated mass flow controllers (200 Lmin ${ }^{-1}$, Tylan General, 2900 Series and $50 \mathrm{~L} \mathrm{~min}^{-1}$ Bronkhorst Hi-TEC) were used to fill and flush the chamber. The facility is equipped with different type of lamps. In this work, 2 to 4 lamps (UV-A T-40 L, Viber Lourmat) providing UV radiation with a maximum emission at $254 \mathrm{~nm}$ were used to generate $\mathrm{OH}$ radicals from the photolysis of $\mathrm{H}_{2} \mathrm{O}_{2}$. The rate coefficient for the reaction of pyridine with $\mathrm{OH}$ was determined relative to that for acetone. The reaction of pyridine with $\mathrm{O}_{3}$ was measured under pseudo first order conditions where the concentration of $\mathrm{O}_{3}$ was in large excess compared to that of pyridine $\left.\left(\left[\mathrm{O}_{3}\right]_{0}>>\text { [pyridine }\right]_{0}\right)$. Ozone was generated by discharge in $\mathrm{O}_{2}$ and its concentration was measured by FTIR . Pyridine and acetone were monitored by using the in-situ FTIR technique and PTR-TOF-MS (Ionicon analytik). The chamber is equipped with a White mirrors system with an optical path of $148 \mathrm{~m}$. This multiple reflection system is coupled to a Fourier Transform InfraRed (FTIR) spectrometer (Nicolet 5700 Magna) used for the detection in situ of organic molecules. Infrared spectra were recorded every 5 minutes by co adding 40 to 130 interferograms with a resolution of $1 \mathrm{~cm}^{-1}$ over the spectral range $600-4000 \mathrm{~cm}^{-1}$. 'The dilution rate was determined by adding $\mathrm{SF}_{6}$ to the air mixture, so experiments were carried out several times and rate dilution values of (0.95 to 1.3$) \times 10^{-5} \mathrm{~s}^{-1}$ were obtained'.

Chemicals: The used chemicals were obtained from Sigma Aldrich: Acetone (99.9\%) and $\mathrm{C}_{5} \mathrm{H}_{5} \mathrm{~N}$ (99.9 \%) were further purified by repeated freeze pump thaw cycles before use. $\mathrm{H}_{2} \mathrm{O}_{2}$ ( $50 \%$ in water) was concentrated by bubbling air through the solution to remove water for several days prior to use. $\mathrm{SF}_{6}$ (Alphagaz 1) and Helium (Alphagaz 1) were provided by Air Liquide

\section{Results and Discussion:}

\section{UV absorption cross-sections of pyridine:}

The absorption cross-section values obtained are presented in Table 1 and shown in Figure 1. The measurements were performed in a series of 50 to $100 \mathrm{~nm}$ adjacent regions with a 10 $\mathrm{nm}$ overlap. The reported values represent the average of 3 to 8 independent measurements at several pressures. The recorded spectra have been found to be reproducible (the variation did not exceed $20 \%$ over the studied spectral range). As seen in Figure 1, the obtained spectrum 
exhibits a broad absorption band in the spectral region 220 - $310 \mathrm{~nm}$ with a maximum of $4.36 \times 10^{-18} \mathrm{~cm}^{2}$ molecule ${ }^{-1}$ located at $249 \mathrm{~nm}$.

Pyridine is isoelectronic with benzene, so the observed absorption band is most probably due to the $\pi-\pi^{*}$ electronic transition. However, due to the presence of nitrogen atom in the aromatic ring the $n-\pi *$ transition is expected to occur and might be overlapping with $\pi-\pi^{*}$ band.

Several studies were found in the literature dealing with the spectroscopic analysis of the UV absorption spectrum of gaseous pyridine $[12,13,14]$. These studies showed that the maximum of absorbance which corresponds to $\pi-\pi^{*}$ transitions is located close to $250 \mathrm{~nm}$. For the transition $\mathrm{n}-\pi^{*}$, the maximum of absorption is located near to $290 \mathrm{~nm}$. However, to our knowledge, no UV absorption cross-sections studies, in the gas phase, exist in the literature for pyridine.

Uncertainties on the obtained cross-sections values were estimated to be lower than $20 \%$ resulting mainly from the uncertainty on the concentration and the purity degree of pyridine. In order to minimize the uncertainty due to wall loss, the cell was heated up to $353 \mathrm{~K}$ and the pressure of pyridine introduced into the cell was largely lower than its vapour pressure. The used sample of pyridine was purified by repeated freeze-pump-thaw cycles before use. Other sources of errors may include the instability of the signal; this error was reduced by averaging several measurements.

\section{Reaction with $\mathrm{OH}$ radicals:}

The rate coefficient for the reaction of $\mathrm{OH}$ with pyridine was measured relative to that of acetone:

$$
\begin{array}{lr}
\text { Pyridine }+\mathrm{OH} \rightarrow \text { products } & \mathrm{k}_{\text {pyridine }} \\
\text { Acetone }+\mathrm{OH} \rightarrow \text { products } & \mathrm{k}_{\text {acetone }}
\end{array}
$$

where $\mathrm{k}_{\text {pyridine }}$ and $\mathrm{k}_{\mathrm{acetone}}$ are the rate coefficients of the reaction of $\mathrm{OH}$ with pyridine and acetone, respectively.

In addition to these reactions, both reactants, pyridine and acetone, may be lost by secondary processes such as dilution, the loss to the wall of the chamber and the photolysis under UV radiation. In order to evaluate these losses, several tests were performed prior to kinetic studies. Measurements were carried out in the absence of radiation for the acetone/pyridine $/ \mathrm{H}_{2} \mathrm{O}_{2} /$ air mixture to check for dark reactions and wall losses. The concentrations of acetone and pyridine were monitored by PTR-TOF-MS and GC/MS during 1 hour. Additional tests were performed in the absence of $\mathrm{H}_{2} \mathrm{O}_{2}$ and under radiation in order to 
determine the loss rates of pyridine and acetone due to photolysis. These tests were performed under light intensities and radiation time similar to those employed during our kinetic experiments (3 to 4 hours). To assess losses of reactants by dilution, $\mathrm{SF}_{6}$ was added to the air mixture to quantify the dilution rate. The global secondary loss rates obtained for acetone was $\mathrm{k}_{\mathrm{P}}$ (acetone) $=1.1 \times 10^{-5} \mathrm{~s}^{-1}$ shows that, the loss of acetone is mainly due to dilution. For pyridine, the global secondary loss rates was $\mathrm{k}_{\mathrm{P}}$ (pyridine) $=2.16 \times 10^{-5} \mathrm{~s}^{-1}$ obtained under radiation is almost the same as that obtained in the absence of radiation showing that the photolysis of this compound is negligible compared to other processes (dilution and wall loss).

The pyridine and acetone concentration-time profiles were described using the following equation:

$$
\ln \frac{[\text { pyridine }]_{0}}{[\text { pyridine }]_{t}}-k_{p} t=\frac{k_{\text {pyridine }}}{k_{\text {acetone }}} \times\left[\ln \frac{[\text { acetone }]_{0}}{[\text { acetone }]_{t}}-k_{p}^{\prime} t\right]
$$

where $[\text { pyridine }]_{0},[\text { pyridine }]_{t}$, [acetone $]_{0}$ and $[\text { acetone }]_{t}$ are the concentrations of the reactants before irradiation and at time t, respectively and $k_{p}$ and $k_{p}^{\prime}$ are the decay rates resulting from secondary losses for pyridine and acetone, respectively.

The rate coefficient for the reaction of pyridine with $\mathrm{OH}$ was derived from the slope of the plot shown in Figure 2 according to equation (2). A good linearity was observed with a correlation coefficient greater than $95 \%$ and an intercept close to zero. A value of $\mathrm{k}_{\text {pyridine }}=(5.4 \pm 0.8) \times 10^{-13} \mathrm{~cm}^{3}$ molecule $\mathrm{s}^{-1}$ was obtained using $\mathrm{k}_{\text {acetone }}=(1.84 \pm 0.25) \times 10^{-13}$ $\mathrm{cm}^{3}$ molecule $\mathrm{e}^{-1} \mathrm{~s}^{-1}$ at $298 \mathrm{~K}$ [15].

The overall error in the rate coefficient value originates from the uncertainty on the rate coefficient of the reference compound $\left(\frac{\Delta k_{r e f}}{k_{r e f}}=13 \%\right)$ and the error on the determination of the slope $\frac{\Delta(\text { slope })}{\text { slope }}$ shown in Figure 2 derived from the least squares analysis $(4 \%)$. The error on the rate coefficient was therefore calculated according to equation (3):

$$
\Delta k=k \times \sqrt{\left[\frac{\Delta k_{\text {ref }}}{k_{\text {ref }}}\right]^{2}+\left[\frac{\Delta(\text { slope })}{\text { slope }}\right]^{2}}
$$


The obtained $k_{\text {pyridine }}$ value is in good agreement with those of $(4.9 \pm 0.4) \times 10^{-13}$ and (5.31 \pm 0.60$) \times 10^{-13} \mathrm{~cm}^{3}$ molecule $\mathrm{s}^{-1}$ reported by Atkinson et al, [2] and Yeung et al, [7], respectively. In their work, Atkinson et al, [2] studied the reaction of pyridine with $\mathrm{OH}$ at $296 \pm 2 \mathrm{~K}$ and atmospheric pressure in a 5800-L, Teflon-coated environmental chamber, with irradiation being provided by a $24-\mathrm{kW}$ xenon arc. The $\mathrm{OH}$ radicals were generated either by the photolysis of methyl nitrite at wavelength $>290 \mathrm{~nm}$ or by the dark $\mathrm{N}_{2} \mathrm{H}_{4}-\mathrm{O}_{3}$ reaction. The reactants and reference compounds were monitored by the FTIR absorption spectroscopy. The rate coefficient of the reaction of pyridine with $\mathrm{OH}$, determined by Yeung et al, [7], was measured using a turbulent flow technique combined with high pressure chemical ionization mass spectrometry at 100 Torr pressure and $298 \mathrm{~K}$. OH radicals were generated using the reaction of $\mathrm{H}$ with $\mathrm{NO}_{2}$.

Moreover, our experimental value is $30 \%$ higher than that of $\mathrm{k}_{\text {pyridine }}=3.7 \times 10^{-13} \mathrm{~cm}^{3}$ molecule $\mathrm{e}^{-1} \mathrm{~s}^{-1}$ obtained by using AOPWIN, 2000 v.1.92 [16] based on SAR calculations [17].

The reaction of pyridine with $\mathrm{OH}$ is expected to proceed mainly by addition on the meta position for which the electronic density is higher than ortho- and para- positions, as reported in previous theoretical studies [7, 18]. In their study, Vivekananda et al, [18], used standard ab-initio and density functional theory (B3LYP)6-31+G(d,p) basis set to study the pyridinehydroxyl adduct. The obtained results showed that $\mathrm{OH}$ addition to the two carbon atoms in the meta- position amounted to $81-98 \%$ of total reactivity and the nitrogen atom was calculated to be virtually unreactive toward $\mathrm{OH}$ attack. Theoretical calculations on the addition of $\mathrm{OH}$ to pyridine have been also performed by Yeung et al, [7] 2003 using the B3LYP/6-31G(d,p) and TST MPW1K/6-31+G(d,p) levels. The meta position was found to be much more favorable than the other positions for $\mathrm{OH}$ addition to pyridine because of the meta-directing nature of the relatively electronegative substituent. However, according to the study carried out by Barckholtz et al, [19], the H-atom abstraction channel seems to become kinetically and thermodynamically preferred over the addition channel at temperature lower than $298 \mathrm{~K}$ in particular for attack ortho- and para- sites.

As expected, the reactivity of pyridine with $\mathrm{OH}$ radicals is slower (2.5 times) than that for benzene $\left(\mathrm{k}_{\text {benzene }}=1.2 \times 10^{-12} \mathrm{~cm}^{3}\right.$ molecule $\mathrm{e}^{-1} \mathrm{~s}^{-1}$ recommanded by IUPAC [20]. This is due to the inclusion of a nitrogen atom into the aromatic ring that lowers the reactivity toward $\mathrm{OH}$ radicals [7] due to the electron-withdrawing effect of the nitrogen atom.

The comparison with pyrrole $\left(\mathrm{C}_{4} \mathrm{H}_{5} \mathrm{~N}\right)$ shows that the reactivity of $\mathrm{OH}$ with pyridine is almost 200 times slower than that of pyrrole [21] suggesting that the radical addition to five- 
membered rings is kinetically preferred and thermodynamically more exoergic than radical addition to six-membered rings [19].

\section{Reaction with $\mathbf{O}_{3}$ :}

The rate coefficient for the reaction of pyridine with $\mathrm{O}_{3}$ was determined under large excess of $\mathrm{O}_{3}$ compared to that of pyridine. The concentration of pyridine was monitored by PTR-TOF-MS and that of $\mathrm{O}_{3}$ by UV absorption. The rate coefficient $k_{\mathrm{O}_{3}}$ of the reaction of pyridine with $\mathrm{O}_{3}$ was determined by monitoring the consumption of pyridine according to the following equations:

$$
\ln \frac{[\text { pyridine }]_{0}}{[\text { pyridine }]_{t}}=k_{\text {obs }}{ }^{t}
$$

where $k_{o b s}=k_{O_{3}}\left[O_{3}\right]+k_{p}(5)$ and $k_{p}$ is the loss rate of pyridine in the absence of $\mathrm{O}_{3}$.

The initial concentrations were $4430 \mathrm{ppb}$ for ozone and in the range 70-200 ppb for pyridine. The loss rates of pyridine in the absence and presence of ozone were determined from the plot showed in Figure 3. In the presence of $\mathrm{O}_{3}$, the monitoring starts 10 minutes after the introduction of ozone into the chamber. $k_{o b s}$ values of $(1.85 \pm 0.4) \times 10^{-5} \mathrm{~s}^{-1}$ and $(2.2 \pm 0.4)$ $\times 10^{-5} \mathrm{~s}^{-1}$ were found in the absence and the presence of ozone, respectively. A value of (3.28 $\pm 1.70) \times 10^{-20} \mathrm{~cm}^{3}$ molecule $\mathrm{s}^{-1}$ was obtained for $k_{\mathrm{O}_{3}}$ according to relation (5).

The reaction of pyridine with $\mathrm{O}_{3}$ has been the subject of only one study carried out by Atkinson et al. [2] by using a 175-L FEP Teflon reaction chamber at $296 \mathrm{~K}$ and 735 Torr of air. The rate coefficient was measured by monitoring the increased rates of $\mathrm{O}_{3}$ decay in the presence of known concentrations of pyridine in large excess compared to that of ozone. An upper limit of $1.1 \times 10^{-20} \mathrm{~cm}^{3}$ molecule $\mathrm{s}^{-1}$ was obtained.

\section{Atmospheric implications:}

The data obtained in this work were used to estimate the tropospheric lifetime, $\tau_{\mathrm{X}}$, of pyridine due to its removal by chemical reaction with atmospheric photo-oxidants $(X=O H$,

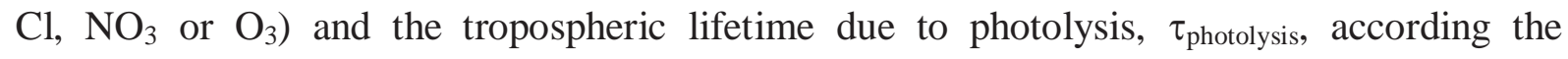
equations (6) and (7):

$$
\tau_{X}=\frac{1}{k_{X}[X]}
$$


where $[X]$ represents the average concentration of the atmospheric photo-oxidant and $k_{x}$ the rate coefficient for the reaction of pyridine with the photo-oxidant. Average global tropospheric concentrations of $1 \times 10^{6}$ molecule $\mathrm{cm}^{-3}$ [2] $1 \times 10^{3}$ molecule $\mathrm{cm}^{-3}$ [22] and $7 \times 10^{11}$ molecule $\mathrm{cm}^{-3}$ [23] for $\mathrm{OH}, \mathrm{Cl}$ and $\mathrm{O}_{3}$ were used, respectively.

$$
\tau_{\text {photolysis }}=\frac{1}{\mathbf{J}_{\mathbf{P}}}
$$

where $J_{p}$ is the averaged photo-dissociation rate constant. $J_{p}$ values were calculated for different zenith angles $\theta$ varying from $20^{\circ}$ to $50^{\circ}$ at $40^{\circ} \mathrm{N}$ latitude corresponding to the morning of a cloudless day using the following relationship:

$$
\mathrm{J}_{\mathrm{p}}=\int \sigma(\lambda) \phi(\lambda) \mathrm{I}(\lambda) \mathrm{d} \lambda
$$

where $\sigma(\lambda)$ is the absorption cross-section at wavelength $\lambda>290 \mathrm{~nm}\left(\mathrm{~cm}^{2}\right.$ molecule ${ }^{-1}$ ) determined in this work, $\phi(\lambda)$ is the primary quantum yield of photodissociation at wavelength $\lambda$, and $\mathrm{I}(\lambda)$ is the actinic flux of the solar radiation at wavelength $\lambda$ (photons $\mathrm{cm}^{-2}$ $\mathrm{s}^{-1}$ ). The actinic flux values at sea level were taken from reference [24]. A quantum yield of unity was used since the overall quantum yield for pyridine is not known. Therefore, the calculated $\mathrm{J}_{\mathrm{p}}$ values represent an upper limit of the photodissociation rate constants, and the deduced lifetimes constitute lower limits. Values of tropospheric lifetimes are summarized in Table 2. Moreover, given the relatively low Henry's constant of pyridine $\left(1.1 \times 10^{-5} \mathrm{~atm} \mathrm{m^{3 }}\right.$ $\mathrm{mol}^{-1}$ [25], it can be can deduced that the photochemical process are the main routes of atmospheric removal of this compound since it is degraded in less than 2 days (Table 2). It should be noted, that photolysis studies of pyridine under natural solar radiation are required in order to confirm our results. In addition, information regarding the reaction products resulting from atmospheric degradation of this species is sorely needed in order to evaluate its atmospheric impact.

\section{Acknowledgements}

The authors would like to acknowledge the programs VOLUBILIS (MA/10/226), PHCMaghreb (32618SA) the Labex Voltaire (ANR-10-LABX-100-01), and the PIVOTS Project for support. 


\section{References:}

[1] Worthing C.F., The Pesticide Manual, 6th ed.; The British Crop Protection Council Publications: Croyden, UK, (1979).

[2] Atkinson R., Tuazon E.C., Wallington T.J., Aschmann S.M., Arey J., Wlner M. and Pitts J.N., Environ. Scl. Technol. 21 (1987), 64-72.

[3] Clemo, G. R., Tetrahedron, 29 (1973) 3987-3990.

[4] Saintjalm, Y. and Moreetesta, P., J. Chromatogr. 198 (1980) 188-192.

[5] Beig, G., Ann. Geophys. 26 (2008) 1181-1187.

[6] Tanner, D. J. and Eisele, F. L., J. Geophys. Res. Atmos. 96 (1991) 1023-1031.

[7] Yeung, L.Y. and Elrod, M.J., J. Phys. Chem. A 107 (2003) 4470-4477.

[8] El Dib G., Chakir A, Mellouki A. J. Phys. Chem. A, 112 (2008) 8731-8736.

[9] Messadia L., El Dib G., Ferhati A., Roth E., Chakir A. Chem. Phys. Let., 529 (2012) 1622.

[10] Bernard, F.; Eyglunent, G.; Daèle, V.; Mellouki, A. J. Phys. Chem. A 114 (2010) 8376-8383.

[11] Bernard, F.; Daele, V.; Mellouki, A.; Sidebottom, H. J. Phys. Chem. A 116 (2012) 6113-6126.

[12] Sponer H., Stücklen H., J. Chem. Phys. 14 (1946) 101- 112.

[13] Olsher U, Spectrochim. Acta. 34A (1978) 211-214.

[14] Bolovinos A., Tsekeris P., Philis J., Pantos E. and Andritsopoulos G., J. Mol. Spectrosc. 103 (1984) 240-256.

[15] Le Calve'S., Hitie D., Le Bras G., and Mellouki A., J. Phys. Chem. A, 102, (1998) 4579-458.

[16] EPI. AOPWIN v.1.92a, 2000. Atmospheric Oxidation Program for Microsoft Windows. U.S. Environmental Protection Agency

[17] Kwok E.S.C. and Atkinson R., Atmos. Environ., 29 (1995) 1685-1695.

[18] Vivekananda S., Wolken J.K. and Turecek F., J. Phys. Chem. A 105 (2001) 9130-9141.

[19] Barckholtz C., Barckholtz T.A., and Hadad C.M., J. Phys. Chem. A 105 (2001) 140-152.

[20] IUPAC: http://iupac.pole-ether.fr/htdocs/datasheets/pdf/HOx_AROM1_HO_benzene.pdf 
[21] Wallington T.J., Int. J. Chem. Kin., 18 (1986), 487-496.

[22] Wingenter, O. W.; Blake, D. R.; Blake, N. J.; Sive, B. C.; Rowland, F. S.; Atlas, E.; Flocke, F. J.Geophys.Res-Atmos. 104 (1999) 21819 - 21828.

[23] Logan J.A. and V. W. J. H. Kirchhoff, J. Geophys. Res. 91 (1986) 7875-7881.

[24] K.L. Demerjian, K.L. Schere, J.T. Peterson, Adv. Environ. Sci. Tech. 10 (1980) 369.

[25] Hawthorne S.B., Sievers R.E., Barkley R.M., Environ. Sci. Tech. 19 (1985) 992-997.

[26] Zhao Z, Huskey DT, Olsen KJ, Nicovich JM, McKee ML, Wine PH., Phys. Chem. Chem. Phys. 9 (2007) 4383-4394. 


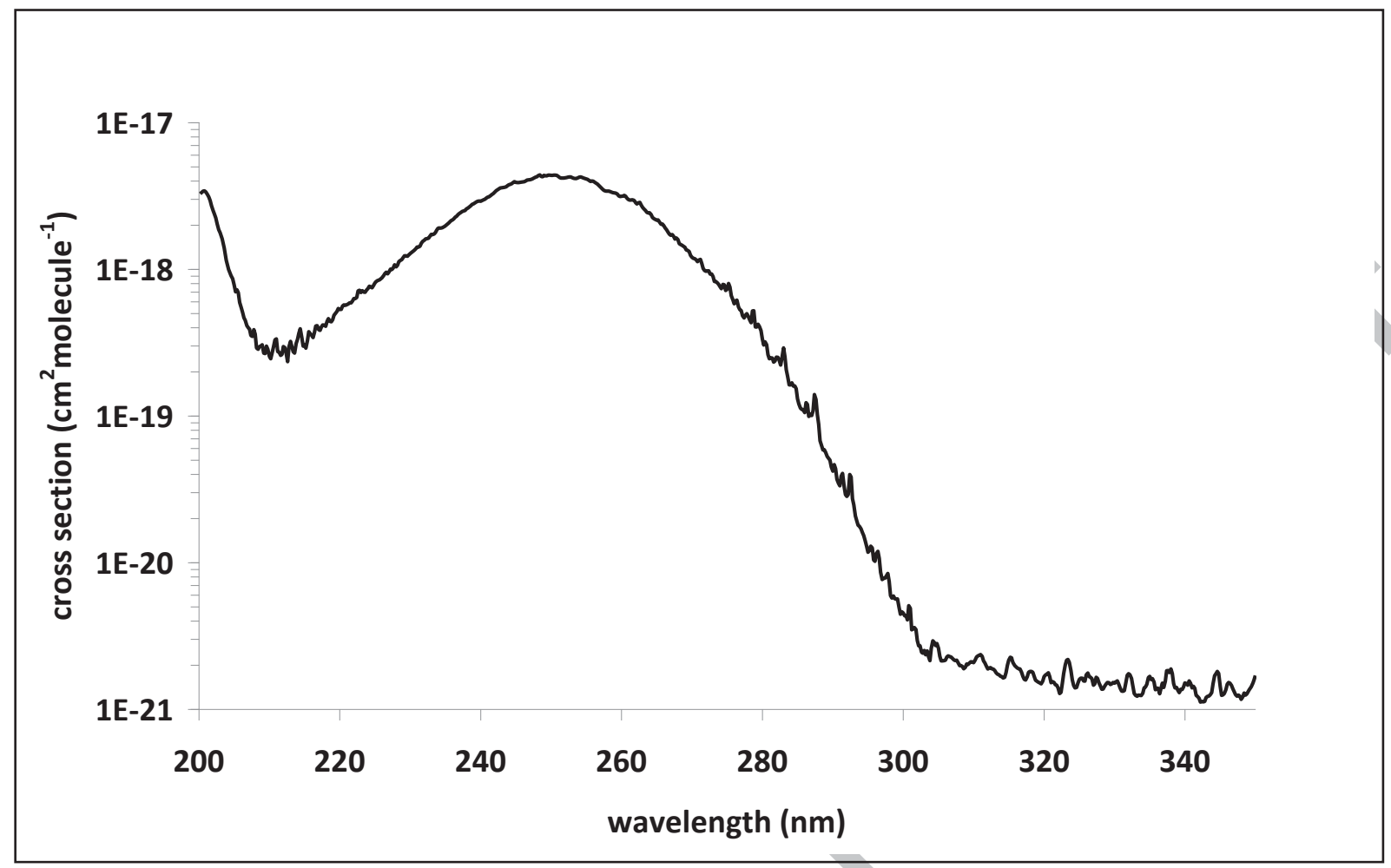

Figure 1: UV absorption spectrum of pyridine obtained in this work over the spectral range 200-350 $\mathrm{nm}$ at $353 \pm 1 \mathrm{~K}$.

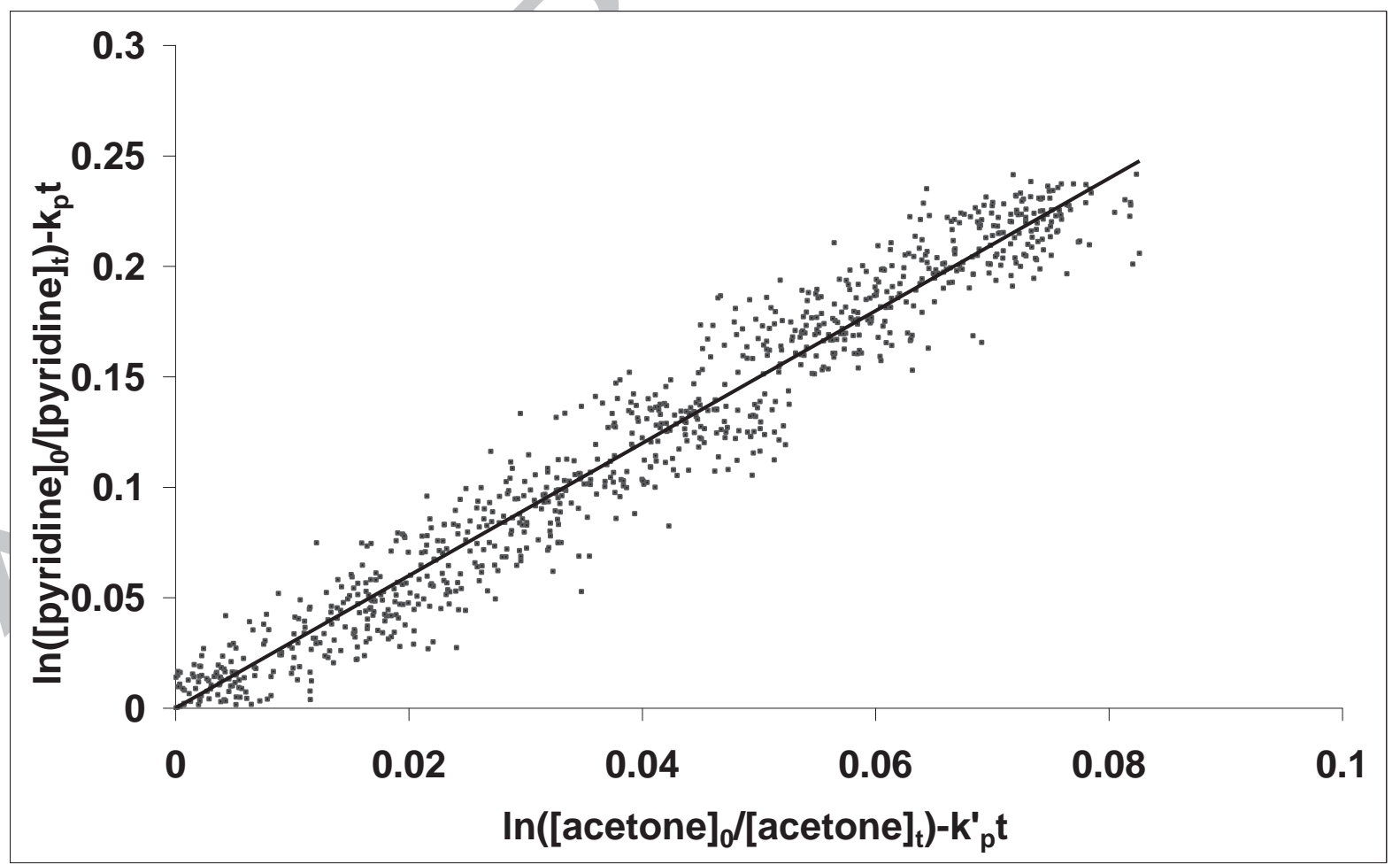

Figure 2: Relative rate plot for the reaction of pyridine with $\mathrm{OH}$ in the presence of acetone. 


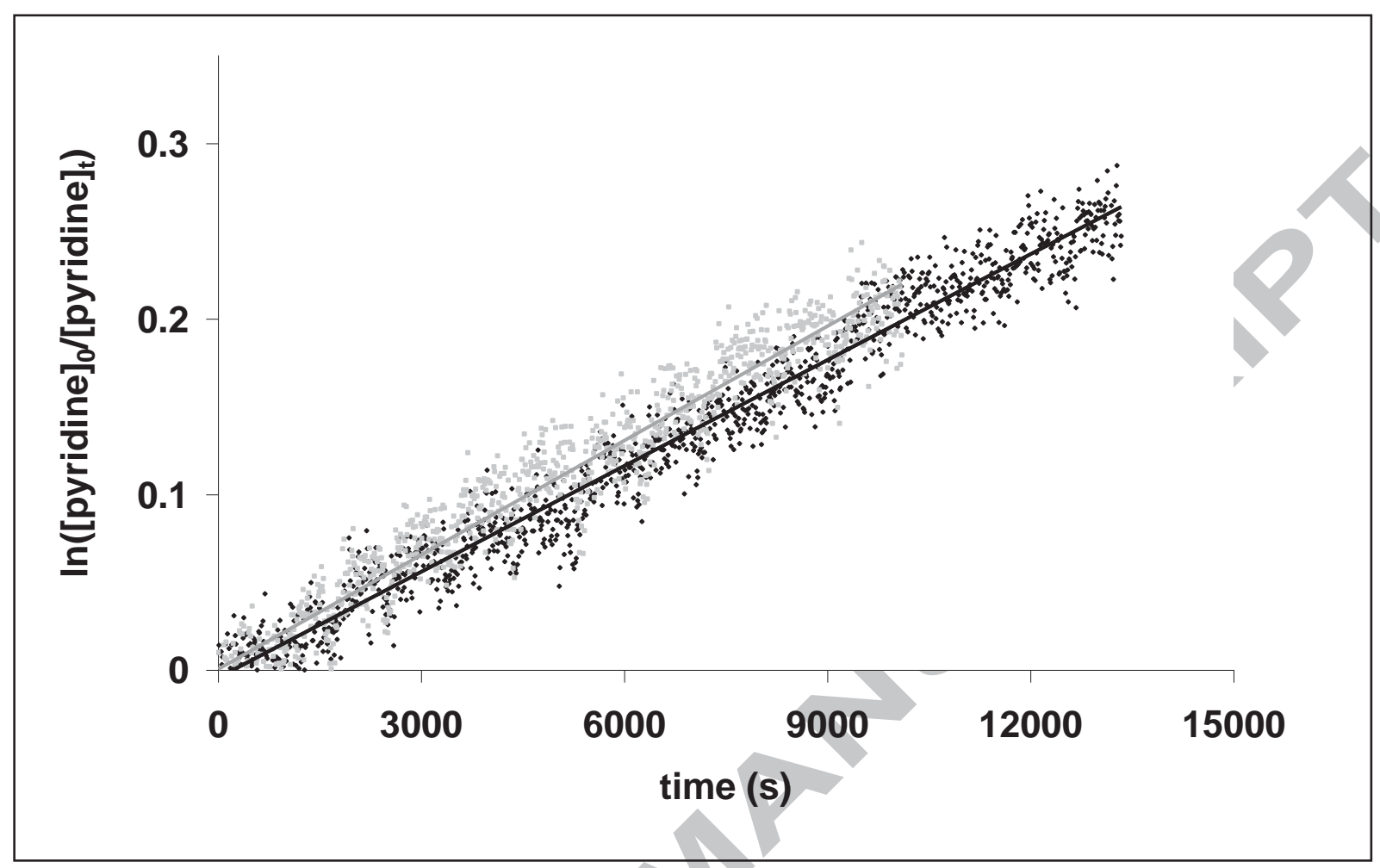

Figure 3: Plot of $\operatorname{Ln} \frac{[\text { pyridine }]_{0}}{[\text { pyridine }]_{t}}$ vs the time in the absence of $\mathrm{O}_{3}$ (black colour) and under pseudo first order conditions where the concentration of $\mathrm{O}_{3}$ is in large excess compared to that of pyridine (grey colour). 
Table 1: Absorption cross-section $\sigma\left(10^{-19} \mathrm{~cm}^{2}\right.$ molecule $\left.{ }^{-1}\right)$ of pyridine over the wavelength range $(\lambda)$ 200-350 $\mathrm{nm}$ at $353 \pm 1 \mathrm{~K}$.

\begin{tabular}{|c|c|c|c|c|c|c|c|}
\hline$\lambda$ & $\sigma$ & $\lambda$ & $\sigma$ & $\lambda$ & $\sigma$ & $\lambda$ & $\sigma$ \\
\hline 200 & 32.49 & 240 & 29.25 & 280 & 3.04 & 319 & 0.02 \\
\hline 201 & 32.91 & 241 & 30.98 & 281 & 2.44 & 320 & 0.02 \\
\hline 202 & 24.40 & 242 & 33.91 & 282 & 2.52 & 321 & 0.02 \\
\hline 203 & 17.10 & 243 & 36.04 & 283 & 3.00 & 322 & 0.01 \\
\hline 204 & 10.50 & 244 & 37.75 & 284 & 1.68 & 323 & 0.02 \\
\hline 205 & 7.00 & 245 & 38.95 & 285 & 1.23 & 324 & 0.01 \\
\hline 206 & 5.49 & 246 & 39.47 & 286 & 1.04 & 325 & 0.02 \\
\hline 207 & 4.02 & 247 & 40.98 & 287 & 0.97 & 326 & 0.02 \\
\hline 208 & 3.15 & 248 & 43.19 & 288 & 0.70 & 327 & 0.01 \\
\hline 209 & 3.03 & 249 & 43.60 & 289 & 0.53 & 328 & 0.01 \\
\hline 210 & 2.42 & 250 & 43.53 & 290 & 0.44 & 329 & 0.02 \\
\hline 211 & 3.13 & 251 & 42.62 & 291 & 0.33 & 330 & 0.02 \\
\hline 212 & 2.83 & 252 & 41.96 & 292 & 0.28 & 331 & 0.01 \\
\hline 213 & 2.90 & 253 & 41.90 & 293 & 0.22 & 332 & 0.02 \\
\hline 214 & 3.30 & 254 & 42.65 & 294 & 0.16 & 333 & 0.01 \\
\hline 215 & 3.14 & 255 & 41.13 & 295 & 0.12 & 334 & 0.01 \\
\hline 216 & 3.44 & 256 & 39.58 & 296 & 0.11 & 335 & 0.02 \\
\hline 217 & 3.68 & 257 & 35.91 & 297 & 0.08 & 336 & 0.01 \\
\hline 218 & 4.09 & 200 & 34.13 & 298 & 0.07 & 337 & 0.01 \\
\hline 219 & 4.59 & 259 & 33.12 & 299 & 0.06 & 338 & 0.02 \\
\hline 220 & 5.28 & 260 & 31.35 & 300 & 0.04 & 339 & 0.01 \\
\hline 221 & 5.71 & 261 & 29.53 & 301 & 0.03 & 340 & 0.02 \\
\hline 222 & 6.39 & 262 & 28.04 & 302 & 0.03 & 341 & 0.01 \\
\hline 223 & 7.15 & 263 & 26.15 & 303 & 0.02 & 342 & 0.01 \\
\hline 224 & 7.50 & 264 & 24.36 & 304 & 0.03 & 343 & 0.01 \\
\hline 225 & 8.25 & 265 & 21.72 & 305 & 0.02 & 344 & 0.02 \\
\hline 226 & 9.06 & 266 & 19.30 & 306 & 0.02 & 345 & 0.01 \\
\hline 227 & 9.91 & 267 & 17.05 & 307 & 0.02 & 346 & 0.02 \\
\hline 228 & 10.04 & 268 & 15.35 & 308 & 0.02 & 347 & 0.01 \\
\hline 229 & 12.28 & 269 & 13.88 & 309 & 0.02 & 348 & 0.01 \\
\hline 230 & 12.85 & 270 & 12.07 & 310 & 0.02 & 349 & 0.01 \\
\hline 231 & 14.39 & 271 & 11.86 & 311 & 0.02 & & \\
\hline 232 & 16.06 & 272 & 9.59 & 312 & 0.02 & & \\
\hline 233 & 17.42 & 273 & 8.25 & 313 & 0.02 & & \\
\hline 234 & 19.11 & 274 & 7.36 & 314 & 0.02 & & \\
\hline 235 & 20.05 & 275 & 7.59 & 315 & 0.02 & & \\
\hline 236 & 21.60 & 276 & 5.75 & 316 & 0.02 & & \\
\hline 237 & 24.37 & 277 & 5.07 & 317 & 0.02 & & \\
\hline 238 & 25.91 & 278 & 4.60 & 318 & 0.02 & & \\
\hline 239 & 28.11 & 279 & 3.84 & 319 & 0.02 & & \\
\hline
\end{tabular}


Table 2 Photodissociation rate constants $\mathrm{J}_{\mathrm{p}}$ (upper limits) as a function of solar zenith angle and the estimated tropospheric lifetimes of pyridine with respect to photolysis and its reactions with atmospheric photooxidants.

\begin{tabular}{|c|c|c|c|c|c|c|c|c|}
\hline \multicolumn{4}{|c|}{ Photodissociation rate constants $\mathrm{J}_{\mathrm{p}}\left(\mathrm{s}^{-1}\right)$} & \multirow{2}{*}{$\tau$ photolysis } & \multirow{2}{*}{$\tau \mathrm{OH}$} & \multirow{2}{*}{$\tau_{\mathrm{NO} 3}$} & \multirow{2}{*}{$\tau_{\mathrm{Cl}}$} & \multirow{2}{*}{$\tau_{\mathrm{O} 3}$} \\
\hline$\theta=20^{\circ}$ & $\theta=30^{\circ}$ & $\theta=40^{\circ}$ & $\theta=50^{\circ}$ & & & & & \\
\hline $8.15 \times 10^{-6}$ & $7.58 \times 10^{-6}$ & $6.71 \times 10^{-6}$ & $5.55 \times 10^{-6}$ & $>1.5 \mathrm{~d}^{(\mathrm{a})}$ & $21 \mathrm{~d}^{(\mathrm{b})}$ & $\bar{T}$ & $100 \mathrm{y}$ & $1 \mathrm{y}$ \\
\hline
\end{tabular}

${ }^{\text {a }}$ value calculated using the photolysis rate determined at $\theta=30^{\circ}$

${ }^{b}$ value calculated by using the rate constant found in this work

${ }^{c}$ value calculated by using the rate constant reported by reference [26] (Zhao et al, 2007) 
Graphical abstract

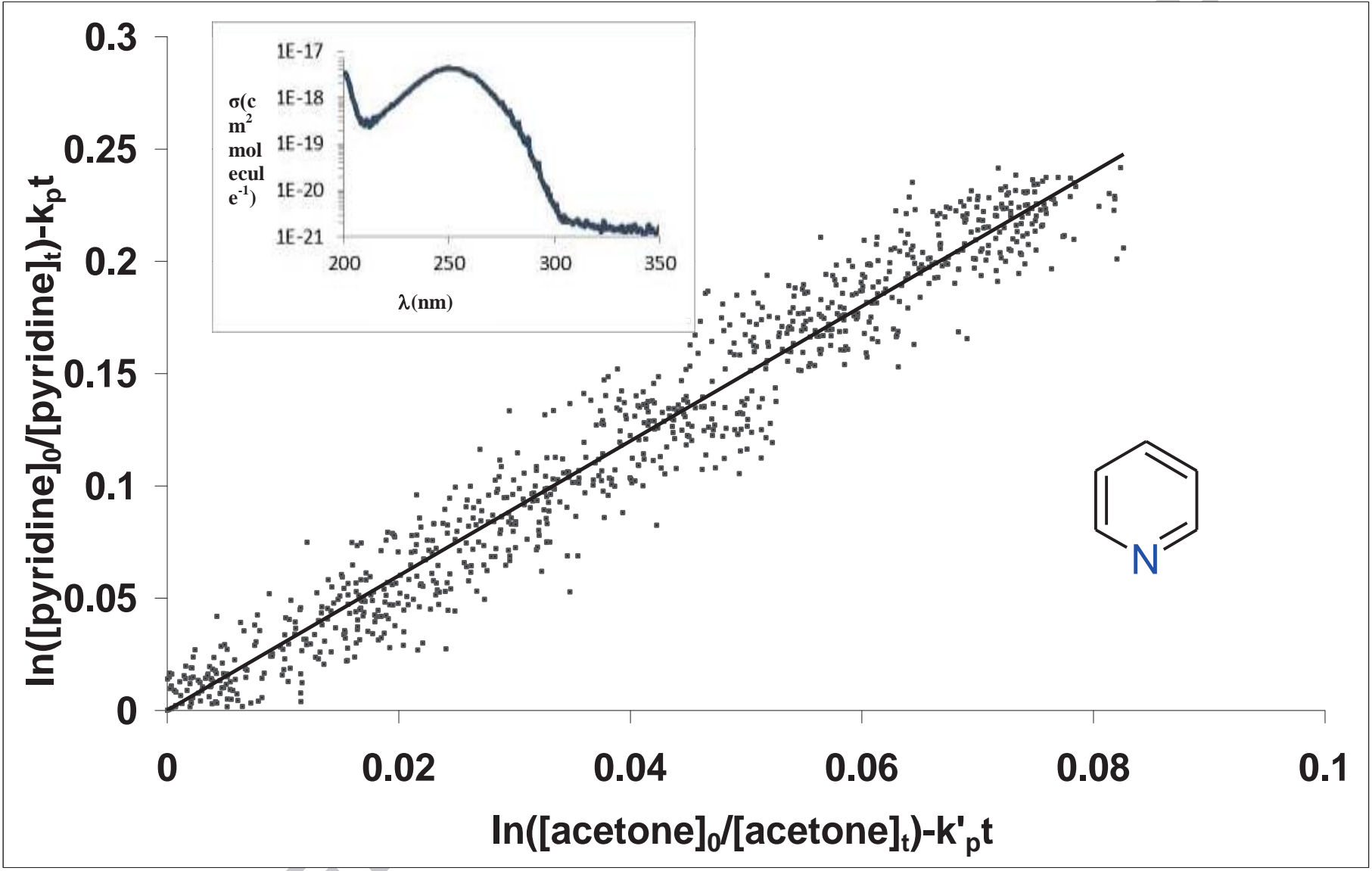




\section{Highlights}

- The UV absorption cross-sections of pyridine have been measured.

- This work provides the kinetic reaction of pyridine with $\mathrm{OH}$ radicals and ozone.

- Results are compared to those found in literature.

- The atmospheric lifetime of pyridine has been estimated with respect to reaction with $\mathrm{OH}$ radicals and ozone. 